CLINICAL STUDY

\title{
Evaluation of the respective influence of thyroid hormones and TSH on blood coagulation parameters after total thyroidectomy
}

\author{
John Yango $^{1}$, Orsalia Alexopoulou ${ }^{1}$, Stephane Eeckhoudt ${ }^{2}$, Cedric Hermans ${ }^{2}$ and Chantal Daumerie ${ }^{1}$ \\ Departments of ${ }^{1}$ Endocrinology and ${ }^{2}$ Hematology, Cliniques Universitaires Saint-Luc, Université Catholique de Louvain, Avenue Hippocrate, 10, \\ B-1200 Brussels, Belgium \\ (Correspondence should be addressed to C Daumerie; Email: chantal.daumerie@uclouvain.be)
}

\begin{abstract}
Background: Several hemostatic abnormalities have been described in hypothyroidism, such as modification of coagulation proteins and bleeding tendency. Although thyroid hormone deficiency is considered to be responsible for these changes, the underlying mechanisms have not yet been established.

Objective: To evaluate the respective influence of peripheral thyroid hormones (free thyroxine) and TSH on blood clotting by assessing coagulation parameters in patients with a history of total thyroidectomy for thyroid cancer, under three different conditions: induced hypothyroidism, euthyroid state, and following recombinant human TSH (rhTSH) administration.

Methods: Coagulation parameters (platelet count, fibrinogen, international normalized ratio, prothrombin time, thrombin time, activated partial thromboplastin time (APTT), factor VIII activity ((FVIII:C), as well as von Willebrand factor antigen (VWF:Ag) and VWF activity using collagen binding assay (VWF:CBA)) were measured in patients with severe hypothyroidism following withdrawal of thyroid hormone replacement therapy, and in the same patients with euthyroidism after restoring replacement treatment (group A), and before and after administering rhTSH (group B).

Results: FVIII:C, VWF:Ag, and VWF:CBA were significantly decreased $(P<0.001)$, whereas APTT was significantly increased $(P<0.001)$ in patients with severe hypothyroidism compared with patients in the euthyroid state. No changes in clotting parameters were observed in patients who received rhTSH therapy.

Conclusion: This prospective study shows that severe short-term hypothyroidism is associated with significantly lower levels of VWF:Ag, VWF:CBA, and FVIII:C. Administration of exogenous TSH has no effect on coagulation parameters. These findings suggest that thyroid hormone deficiency is likely to be the main cause of coagulation alterations in patients with hypothyroidism.
\end{abstract}

European Journal of Endocrinology 164 599-603

\section{Introduction}

Hypothyroidism has been associated with various abnormalities of the coagulation system (1-7). These modifications involve both primary and secondary hemostasis, and may range from minor subclinical alterations to significant clinical disturbances. Acquired von Willebrand disease is the most relevant coagulation abnormality in hypothyroidism (8-11). Published data, although limited, suggest that the coagulation and fibrinolytic systems are disturbed in different ways, depending on the severity of hypothyroidism (12-17). Thus, the risk of thrombosis may be increased in patients with subclinical or moderate hypothyroidism, whereas there may be an increased bleeding tendency in patients presenting severe hypothyroidism. Following thyroid hormone replacement therapy $(18,19)$, these abnormalities tend to regress.
The mechanisms accounting for coagulation abnormalities in hypothyroidism are not well established. Most abnormalities have been attributed to decreased synthesis or activity of clotting factors, including von Willebrand factor (VWF) and factor VIII (FVIII:C), or to decreased response to adrenergic stimulation (enhanced VWF release from endothelial cells) due to thyroid hormone deficiency $(1,6,7)$. Other authors have suggested that autoimmunity may be involved $(20,21)$.

The aim of this study was to evaluate in a homogenous population (after total thyroidectomy) the respective influence of thyroid hormone deficiency (after withdrawal of replacement therapy) and high TSH level (following recombinant human TSH (rhTSH) administration), on the hemostasis parameters, in order to determine whether increased serum TSH levels despite normal free thyroid hormone concentrations could influence the coagulation system. 


\section{Patients and methods}

\section{Patients}

Between January and September 2009, a total of 52 consecutive patients having undergone total thyroidectomy for differentiated thyroid cancer were prospectively included in our study and followed up at the outpatient clinic of the Saint Luc University Hospital's Endocrinology Department, in Brussels. Patients were examined for any recurrent or residual disease in severe hypothyroidism after withdrawal of thyroid hormone replacement therapy in group A $(n=22,18$ women and 4 men; mean age: $40 \pm 13$ years) and after i.m. injection of recombinant rhTSH (Thyrogen $0.9 \mathrm{mg}$ : TSH $\alpha$ for injection) in group B $(n=30,22$ women and 8 men; mean age: $49 \pm 13$ years). All patients had received radioactive iodine treatment after total thyroidectomy. None of the patients had a history of blood coagulation disorders or had received anticoagulants. The study was approved by the Universite catholique de Louvain's ethics committee for human studies, and informed consent was obtained from each patient prior to study entry.

\section{Laboratory analyses}

In group A, blood samples were first collected in severe hypothyroidism 4-6 weeks after withdrawal of thyroid hormone replacement therapy, and then in euthyroidism 6-8 weeks after restarting treatment. In group B, rhTSH $(0.9 \mathrm{mg})$ was administered intramuscularly for two consecutive days in order to raise TSH concentrations to severe hypothyroidism levels. Blood samples were obtained before rhTSH administration and 3 days after the first rhTSH injection, which corresponded to the TSH peak.

Fully automated chemiluminescent immunoassays performed using the Dxl system (Beckman Coulter, Inc., Brea, CA, USA) were used to measure free thyroxine $\left(\mathrm{FT}_{4}\right.$; normal range $0.6-1.3 \mathrm{ng} / \mathrm{dl}$ ) and TSH (normal range $<3 \mu \mathrm{U} / \mathrm{ml}$ ). The following coagulation parameters were measured: platelet count using the Sysmex XE2100 (Mundelein, IL, USA) (normal range 150-350 10\% $/ \mu \mathrm{l}$ ); fibrinogen using the thrombin reagent from Siemens (Marburg, Germany; normal range 150-450 mg/dl); prothrombin time using Innovin from Siemens (normal range 9-14s), converted into the international normalized ratio (INR; normal range $0.8-1.3$ ); thrombin time using thromboclotin from Siemens (normal range 15-24 s); activated partial thromboplastin time (APTT) using Actin FS from Siemens (normal range 20-33 s); chronometric determination of FVIII levels (normal range 50-150\%) using Actin FS, Standard Human Plasma, and FVIII:C-deficient plasma from Siemens; VWF activity in the plasma using the collagen binding assay (VWF:CBA, normal range 50-150\%), and VWF antigen using the VWF-Ag reagent from Siemens (normal range 50-150\%). All hematological and biochemical tests, including thyroid function, were performed in the University Hospital using routine assays. The blood group was also determined.

\section{Statistical methods}

Statistical analyses were performed using the Statistical Package for Social Sciences (SPSS statistical software version 15.0; SPSS, Inc., Chicago, IL, USA). Withingroup comparisons were carried out using Student's paired two-tailed $t$-test for normally distributed variables, while the Wilcoxon signed-rank test was performed for non-normally distributed parameters. Between-group differences were evaluated using the one-way ANOVA test or the non-parametric MannWhitney $U$ test when appropriate. Differences in proportions were evaluated using the $\chi^{2}$ test. Results were expressed as mean \pm s.D. $P$ values $<0.05$ were considered statistically significant.

\section{Results}

Patients' main characteristics are summarized in Table 1. No significant difference was found between both groups, with the exception of age and TSH, which were significantly higher in group B than in group A $(P<0.05)$. Severe hypothyroidism induced several hemostatic disturbances, as illustrated in Table 2. VWF:CBA, VWF:Ag, and F VIII:C levels were significantly decreased $(P<0.001)$, while APTT was significantly increased $(P<0.001)$ in severe hypothyroidism, compared with euthyroidism. None of the patients with severe hypothyroidism developed acquired von Willebrand disease. There was no significant difference with respect to the platelet count, prothrombin time, thrombin time, and INR between severe hypothyroidism and euthyroidism. However, in group B, hemostatic parameters administration did not significantly differ 3 days after rhTSH from the euthyroid state (Table 3).

Table 1 Clinical characteristics of patients. Results are given as either mean \pm S.D. or number $(n)$.

\begin{tabular}{lll}
\hline & Group A $(n=22)$ & Group B $(n=30)$ \\
\hline Gender (F/M) & $18 / 4$ & $22 / 8$ \\
Age (years) & $40 \pm 13$ & $49 \pm 13^{*}$ \\
BMl (kg/m $\left.{ }^{2}\right)$ & $25.7 \pm 4.6$ & $25.8 \pm 3.5$ \\
SBP (mmHg) & $120 \pm 16$ & $130 \pm 15$ \\
DBP (mmHg) & $74 \pm 11$ & $79 \pm 08$ \\
Current smoker $(n)$ & $3 / 22$ & $4 / 30$ \\
Blood group & & \\
O $(n=17)$ & 6 & 11 \\
A $(n=25)$ & 11 & 14 \\
B $(n=9)$ & 5 & 4 \\
AB $(n=1)$ & 0 & 1
\end{tabular}

BMI, body mass index; SBP, systolic blood pressure; DBP, diastolic blood pressure; $\mathrm{F}$, female; $\mathrm{M}$, male. ${ }^{\star} P<0.05$. 
Table 2 Hemostatic parameters in group A. Results are presented as mean \pm s.D. or median (Percentile 5-Percentile 95)*.

\begin{tabular}{lllc}
\hline & Hypothyroidism $(n=22)$ & Euthyroidism $(n=22)$ & $\boldsymbol{P}$ value \\
\hline $\mathrm{FT}_{4}(0.6-1.3 \mathrm{ng} / \mathrm{dl})^{*}$ & $0.2(0.0-0.4)$ & $1.3(0.9-1.6)$ & $<0.001$ \\
TSH $(<3 \mu \mathrm{U} / \mathrm{ml})^{*}$ & $87.3(34.0-152.7)$ & $0.33(0.2-3.3)$ & $<0.001$ \\
Fibrinogen $(150-450 \mathrm{mg} / \mathrm{dl})$ & $294.2 \pm 113.5$ & $306.0 \pm 48.7$ & $\mathrm{NS}$ \\
Platelets $(150-35010 \% / \mu \mathrm{l})$ & $269.9 \pm 40.2$ & $259.3 \pm 45.6$ & $\mathrm{NS}$ \\
TT $(15-25 \mathrm{~s})$ & $20.2 \pm 1.2$ & $19.5 \pm 1.2$ & $\mathrm{NS}$ \\
PT $(9-14 \mathrm{~s})$ & $10.7 \pm 0.3$ & $10.8 \pm 0.3$ & $\mathrm{NS}$ \\
INR $(0.8-1.3)$ & $0.9 \pm 0.03$ & $0.9 \pm 0.04$ & $<$ \\
APTT $(20-33 \mathrm{~s})$ & $27.8 \pm 2.3$ & $25.2 \pm 1.6$ & $<0.001$ \\
VWF:CBA (50-150\%) & $102.6 \pm 40.8$ & $140.5 \pm 45.6$ & $<0.001$ \\
VWF:Ag $(50-150 \%)$ & $97.4 \pm 35.9$ & $120.7 \pm 33.5$ & $<0.001$ \\
FVIII:C (50-150\%) & $109.3 \pm 39.4$ & $144.5 \pm 33.3$ & $<0.001$ \\
\hline
\end{tabular}

$\mathrm{FT}_{4}$, free thyroxine; $\mathrm{TSH}$, thyroid stimulating hormone; TT, thrombin time; PT, prothrombin time; INR, international normalized ratio; APTT, activated partial thromboplastin time; VWF:CBA, von Willebrand factor activity; VWF:Ag, von Willebrand factor antigen; FVIII:C, factor VIII activity; NS, not significant.

As expected, patients with blood group $O$ had significantly lower levels of VWF:Ag, VWF:CBA, and FVIII:C than patients with non-O blood groups $(P<0.05$; data not shown).

\section{Discussion}

In this prospective study, we evaluated in patients sharing the same etiology, the respective influence of thyroid hormone deficiency and of an increased TSH levels with normal free thyroid hormone concentrations on coagulation parameters. Our data demonstrate that thyroid hormone deficiency is likely to be the main cause of coagulation disorders in hypothyroidism. High TSH levels with normal free thyroid hormones have no influence on hemostatic parameters. This is also supported by the reversibility of abnormalities following thyroid hormone replacement therapy. Our study confirms the recent Debeij's work on the effect of changes in $\mathrm{T}_{4}$ and $\mathrm{TSH}$ levels on the coagulation system. Their results show that changes in coagulation factors related to thyroid function are mainly mediated by $\mathrm{T}_{4}$ and not by TSH (increasing levels of FVIII, FIX, VWF and fibrinogen with rising levels of $\mathrm{T}_{4}$ ) (22).

The mechanisms underlying coagulation abnormalities during hypothyroidism remain unknown (3) but may be accounted for by decreased synthesis of clotting factors in hypothyroidism (1-3, 6, 7). Low levels of VWF in hypothyroidism could be due to either decreased protein synthesis or decreased response to adrenergic stimulation (enhanced VWF release from endothelial cells) (5-10). Liu Longbin et al. (23) have demonstrated that the interaction between thyroid hormones and $\beta$-adrenergic receptors could induce VWF release. In addition, all clotting factors, except VWF, are synthesized by the liver (1). As hepatocytes contain nuclear thyroid hormone receptors, the interaction between thyroid hormones and their receptors could play a major role in the synthesis of blood clotting factors (24). This suggests that variations in thyroid hormone levels (hyperthyroidism or hypothyroidism) could be associated with increased or decreased concentrations of coagulation factors. Moreover, clinically overt hypothyroidism is associated with an increased risk of bleeding, whereas overt hyperthyroidism is more likely to cause thrombosis (1-2). In our study, patients with

Table 3 Hemostatic parameters in group B. Results are presented as mean \pm s.D. or median (Percentile 5-Percentile 95)*

\begin{tabular}{lllc}
\hline & After rhTSH $(n=30)$ & Before rhTSH $(n=30)$ & $\boldsymbol{P}$ value \\
\hline TSH $(<3 \mu \mathrm{U} / \mathrm{ml})^{*}$ & $138.0(67.0-362.5)$ & $0.2(0.1-3.2)$ & $<0.001$ \\
Fibrinogen $(150-450 \mathrm{mg} / \mathrm{dl})$ & $273.3 \pm 54.3$ & $270.5 \pm 53.2$ & $\mathrm{NS}$ \\
Platelets $\left(150-35010^{6} / \mu \mathrm{l}\right)$ & $246.8 \pm 78.3$ & $258.9 \pm 87.2$ & $\mathrm{NS}$ \\
TT $(15-33 \mathrm{~s})$ & $19.4 \pm 1.4$ & $19.4 \pm 1.2$ & $\mathrm{NS}$ \\
PT $(9-14 \mathrm{~s})$ & $10.7 \pm 0.4$ & $10.7 \pm 0.4$ & $\mathrm{NS}$ \\
INR $(0.8-1.3)$ & $0.99 \pm 0.04$ & $0.95 \pm 0.18$ & $\mathrm{NS}$ \\
APTT $(20-33 \mathrm{~s})$ & $24.4 \pm 1.7$ & $24.4 \pm 1.7$ & $\mathrm{NS}$ \\
VWF:CBA $(50-150 \%)$ & $145.1 \pm 46.3$ & $150.1 \pm 45.2$ & $\mathrm{NS}$ \\
VWF:Ag $(50-150 \%)$ & $130.5 \pm 38.7$ & $134.5 \pm 38.2$ & $\mathrm{NS}$ \\
FVIII:C $(50-150 \%)$ & $152.3 \pm 32.6$ & $154.5 \pm 34.3$ & \\
\hline
\end{tabular}

TT, thrombin time; PT, prothrombin time; INR, international normalized ratio; APTT, activated partial thromboplastin time; VWF:CBA, von Willebrand factor activity; VWF:Ag, von Willebrand factor antigen; FVIII:C, factor VIII activity; NS, not significant. 
severe hypothyroidism had significantly decreased levels of VWF:Ag, VWF:CBA, and FVIII:C, associated with prolonged APTT (reflecting reduced FVIII:C). These modifications were reversible after thyroid hormone replacement therapy. However, no case of acquired von Willebrand disease occurred, probably due to the short duration of hypothyroidism. It is not unlikely that in prolonged severe hypothyroidism (e.g. in auto-immune hypothyroidism), the change in coagulation parameters could be more pronounced. Our findings demonstrate that thyroid hormone deficiency may be associated with significant alterations of hemostasis due to a decrease in VWF:Ag, VWF:CBA, and FVIII:C.

Hypothyroidism (overt or subclinical) could also be associated with increased cardiovascular risk, although the mechanisms are not clearly defined (25-27). This association could be explained through the endothelial dysfunction described in hypothyroidism, which plays a major role in the development of atherosclerosis in addition to classical cardiovascular risk factors. This suggests that thyroid hormone deficiency may be linked to atherosclerosis (increased cardiovascular risk). This assumption is supported by the role that thyroid hormones play in improving endothelium-dependent vasodilatation by restoring nitric oxide (NO) availability $(27,28)$, but direct effects of TSH on vascular endothelium have not been investigated. Napoli et al. (29) have evaluated whether TSH had any effects on vascular hemostasis in patients who received rhTSH. Their results provided evidence that rhTSH acutely enhanced vascular reactivity through mechanism involving endothelium-mediated vasodilatation and independent of changes in thyroid hormones. They suggest that the effect of TSH on endothelial function is probably mediated by its interaction with the TSH receptors present on endothelial cells. Other studies have demonstrated that rhTSH administration induced endothelial function impairment $(30,31)$. VWF activity could be considered as a marker of endothelium dysfunction in patients with cardiovascular disease $(32,33)$. As VWF is synthesized and stored in endothelial cells, its release may be disturbed by endothelial dysfunction or activation (32-34). In our study, no significant modifications of FVIII:C, VWF:Ag, VWF:CBA, and other hemostatic parameters were observed in patients receiving rhTSH, with TSH levels typical of severe hypothyroidism. This suggests that increased TSH concentrations after rhTSH administration did not influence VWF levels or other hemostatic parameters.

In previous studies, subjects with blood group $\mathrm{O}$ have been reported to exhibit 20-30\% lower levels of VWF antigen and activity, compared with subjects with non-O blood groups (34-37). In line with these data, we found an influence of $\mathrm{ABO}$ blood groups on plasma VWF and FVIII levels.

In conclusion, our study shows that thyroid hormones have a direct influence on hemostatic parameters. Patients with severe hypothyroidism may have a risk of mild-to-moderate bleeding tendency. The administration of recombinant rhTSH seems to have no significant influence on hemostatic parameters.

\section{Declaration of interest}

The authors declare that there is no conflict of interest that could be perceived as prejudicing the impartiality of the research reported.

\section{Funding}

This research did not receive any specific grant from any funding agency in the public, commercial or not-for-profit sector.

\section{Acknowledgements}

We would like to thank Prof. D Maiter, Department of Endocrinology, and Prof. F Jamar, Department of Nuclear Medicine, Saint Luc University Hospital, for their participation in recruiting patients for the clinical trial.

\section{References}

1 Hoefbauer LC \& Heufelder AE. Coagulation disorders in thyroid diseases. European Journal of Endocrinology 1997136 1-7. (doi:10. 1530/eje.0.1360001)

2 Squizzato A, Romualdi E, Buller HR \& Gerdes VEA. Thyroid dysfunction and effects on the coagulation and fibrinolysis: a systematic review. Journal of Clinical Endocrinology and Metabolism 200792 2415-2420. (doi:10.1210/jc.2007-0199)

3 Franchini M, Montagnana M, Manzato F \& Vescovi PP. Thyroid dysfunction and hemostasis: an issue still unresolved. Seminars in Thrombosis and Hemostasis 200935 288-294. (doi:10.1055/ s-0029-1222607)

4 Franchini M. Hemostasis and thyroid diseases revisited. Journal of Endocrinological Investigation 200427 886-892.

5 Franchini M, Lippi G, Manazato F, Vescovi PP \& Tagher G. Hemostatic abnormalities in endocrine and metabolic disorders. European Journal of Endocrinology 2010162 439-451. (doi:10. 1530/EJE-09-0958)

6 Myrup B, Bregengard C \& Faber J. Primary haemostasis in thyroid disease. Journal of Internal Medicine 1995238 59-63. (doi:10. 1111/j.1365-2796.1995.tb00899.x)

7 Ford HC \& Carter JM. Haemostasis in hypothyroidism. Postgraduate Medical Journal 199066 280-284. (doi:10.1136/pgmj.66.774. 280)

8 Dalton RG, Dewar MS, Savidge GF, Kernoof PB, Matthews KB \& Preston FE. Hypothyroidism as a cause of acquired von Willebrand's disease. Lancet 19871 1007-1009. (doi:10.1016/ S0140-6736(87)92272-0)

9 Manfredi E, Zaane BV, Gerdes VEA, Brandjes DPM \& Squizzato A. Hypothyroidism and acquired von Willebrand syndrome: a systematic review. Haemophilia 200814 423-433. (doi:10. $1111 /$ j.1365-2516.2007.01642.x)

10 Franchini M, Zugni C, Veneri D, Gandini G, Lippi G, Manzato F \& Brazzarola P. High prevalence of acquired von Willebrand's syndrome in patients with thyroid diseases undergoing thyroid surgery. Haematologica 200489 1341-1346.

11 Michiels JJ, Bememan Z \& Van der Planken M. Acquired von Willebrand syndrome type 1 in hypothyroidism: reversal after treatment with thyroxine. Clinical and Applied Thrombosis/Hemostasis 20017 113-115. (doi:10.1177/107602960100700206)

12 Muller B, Tsakiris DA, Roth CB, Guglielmetti M, Staub JJ \& Marbet GA. Haemostatic profile in hypothyroidism as potential 
risk factor for vascular or thrombotic disease. European Journal of Clinical Investigation 200131 131-137. (doi:10.1046/j.13652362.2001.00777.x)

13 Homonncik M, Gessl A, Ferlitsch A, Jilma B \& Vierhapper H. Altered platelet plug formation in hyperthyroidism and hypothyroidism. Journal of Clinical Endocrinology and Metabolism 200792 3006-3012. (doi:10.1210/jc.2006-2644)

14 Erem C. Blood coagulation, fibrinolytic activity and lipid profile in subclinical thyroid disease: subclinical hyperthyroidism increases plasma factor X activity. Clinical Endocrinology 200664 323-329. (doi:10.1111/j.1365-2265.2006.02464.x)

15 Erem C, Ersoz HO, Karti Ss, Ukinc K, Hacihasanoglu A, Deger O \& Telatar M. Blood coagulation and fibrinolysis in patients with hyperthyroidism. Journal of Endocrinological Investigation 200225 345-350.

16 Chadarevian R, Bruckert E, Leenhardt L, Giral P, Ankri A \& Turpin G. Components of the fibrinolytic system are differently altered in moderate and severe hypothyroidism. Journal of Clinical Endocrinology and Metabolism 200186 732-737. (doi:10.1210/ jc.86.2.732)

17 Chadarevian R, Bruckert E, Ankri A, Beucler I, Giral P \& Turpin G. Relationship between thyroid hormones and plasma D-dimer levels. Thrombosis and Haemostasis 199879 99-103.

18 Gullu S, Sav H \& Kamel N. Effects of levothyroxine treatment on biochemical and hemostasis parameters in patients with hypothyroidism. European Journal of Endocrinology 2005152 355-361. (doi:10.1530/eje.1.01857)

19 Chadarevian R, Jublanc C, Bruckert E, Giral P, Ankri A, Leenhardt L, Chapman J \& Turpin G. Effect of levothyroxine replacement therapy on coagulation and fibrinolysis in severe hypothyroidism. Journal of Endocrinological Investigation 200528 398-404.

20 Franchini M, Lippi G, Manzato F \& Vescovi PP. Thyroid associated auto-immune coagulation disorders. Journal of Thrombosis and Thrombolysis 200928 362-365. (doi:10.1007/s11239-0080253-7)

21 Meiklejohn DJ \& Watson HG. Acquired haemophilia in association with organ-specific auto-immune disease. Haemophilia 20017 523-525. (doi:10.1046/j.1365-2516.2001.00519.x)

22 Debeij Jan, Suzanne CC, van Zaane Bregje, Smit Johannes WA, Corssmit Eleonore PM, Rosendaal Frits R, Romijn Johannes A \& Dekkers Olaf M. The effect of changes in thyroxine and thyroid stimulating hormone levels on the coagulation system. Journal of Thrombosis and Haemostasis 20108 2823-2826. (doi:10.1111/j. 1538-7836.2010.04054.x)

23 Liu Longbin, Wang Xiangbin, Lin Zhusan \& Wu Hanwen. Elevated plasma levels of VWF:Ag in hyperthyroidism are mediated through beta-adrenergic receptors. Endocrine Research 199319 123-133. (doi:10.3109/07435809309033019)

24 Shih CH, Chen SL, Yan CC, Huang YH, Chen CD, Lee YS \& Lin KH. Thyroid hormone receptor-dependent transcriptional regulation of fibrinogen and coagulation proteins. Endocrinology 2004145 2804-2814. (doi:10.1210/en.2003-1372)

25 Lekakis J, Papamichael C, Alevizaki M, Piperingos G, Marafelia P, Mantzos J, Stamateloulous S \& Koutras DA. Flow-mediated, endothelium-dependent vasodilatation is impaired in subjects with hypothyroidism, borderline hypothyroidism, and high-normal serum thyrotropin (TSH) values. Thyroid 1997 7 411-414. (doi:10. 1089/thy.1997.7.411)

26 Taddei S, Caraccio N, Virdis A, Dardano A, Versari D, Ghiadoni L, Salvetti A, Ferrannini E \& Monzani F. Impaired endothelium-dependent vasodilatation in subclinical hypothyroidism: beneficial effect of levothyroxine therapy. Journal of Clinical Endocrinology and Metabolism $2003 \mathbf{8 8}$ 3731-3737. (doi:10.1210/jc.2003-030039)

27 Papaionnou GI, Lagasse M, Mather JF \& Thompson PD. Treating hypothyroidism improves endothelium function. Metabolism 2004 53 278-279. (doi:10.1016/j.metabol.2003.10.003)

28 Cappola AR \& Ladenson PW. Hypothyroidism and atherosclerosis. Journal of Clinical Endocrinology and Metabolism $2003 \mathbf{8 8}$ 2438-2444. (doi:10.1210/jc.2003-030398)

29 Napoli R, Biondi B, Guardasole V, D’Anna C, DE Sena A, Pirozzi C, Terracciano D, Mazzarella C, Matarazzo M \& Sacca L. Enhancement of vascular endothelial function by recombinant human thyrotropin. Journal of Clinical Endocrinology and Metabolism 2008 93 1959-1963. (doi:10.1210/jc.2007-2797)

30 Giusti M, Valenti S, Guazzino B, Molinari E, Cavallero D, Augeri C \& Minuto A. Circulating nitric oxide is modulated by recombinant human TSH during monitoring of thyroid cancer remnant. Journal of Endocrinological Investigation 200326 1192-1197.

31 Dardano A, Ghiardoni L, Plantinga Y, Caraccio N, Bemi A, Duranti E, Taddei S, Ferrannini E, Salvetti A \& Monzani F. Recombinant human thyrotropin reduces endothelium-dependent vasodilatation in patients monitored for differentiated thyroid carcinoma. Journal of Clinical Endocrinology and Metabolism 2006 91 4175-4178. (doi:10.1210/jc.2006-0440)

32 Borawski J, Nauminck B, Pawlak K \& Mysliwiec M. Endothelial dysfunction marker von Willebrand factor antigen in haemodialysis patients: associations with pre-dialysis blood pressure and acute phase response. Nephrology, Dialysis, Transplantation 2001 16 1442-1447. (doi:10.1093/ndt/16.7.1442)

33 Horvath B, Hegedus D, Szapary L, Marton Z, Alexy T, Koltai K, Czopf L, Wittmann I, Jurcskay I, Kalman T \& Kesmarky G. Measurement of von Willebrand factor as the marker of endothelial dysfunction in vascular diseases. Experimental and Clinical Cardiology 20049 31-34.

34 Lip GY \& Blann AD. von Willebrand factor and its relevance to cardiovascular disorders. British Heart Journal $1995 \mathbf{7 4} 580-583$. (doi:10.1136/hrt.74.6.580)

35 Franchini M, Capra F, Targher G, Montagnana M \& Lippi G. Relationship between ABO blood group and von Willebrand factor levels: from biology to clinical implications. Thrombosis Journal 20075 14. (doi:10.1186/1477-9560-5-14)

36 Gill JC, Endres-Brooks J, Bauer PJ, Marks WJ \& Montgomery RR. The effect of $\mathrm{ABO}$ group on the diagnosis of von Willebrand disease. Blood 198769 1691-1695.

37 Kumar S, Pruthi RK \& Nichols William L. Acquired von Willebrand disease. Mayo Clinic Proceedings 200277 181-187. (doi:10.4065/77.2.181)

Received 20 January 2011

Accepted 21 January 2011 